\title{
Interface Dynamics in $\mathrm{Ag}-\mathrm{Cu}_{3} \mathrm{P}$ Nanoparticle Heterostructures
}

Michael S. Seifner, ${ }^{*,+, \neq}$ Markus Snellman, ${ }^{\ddagger, \S}$ Ofentse A. Makgae, ${ }^{,+\neq}$Krishna Kumar, ${ }^{\dagger, \ddagger}$ Daniel Jacobsson, ${ }^{+, \neq, l}$ Martin Ek, ${ }^{+, \ddagger}$ Knut Deppert, ${ }^{,, \S}$ Maria E. Messing, ${ }^{\ddagger, \S}$ and Kimberly A. Dick ${ }^{*,+, \neq}$

† Centre for Analysis and Synthesis, Lund University, Box 124, 22100 Lund, Sweden

‡ NanoLund, Lund University, Box 118, 22100 Lund, Sweden

$\S$ Solid State Physics, Lund University, Box 118, 22100 Lund, Sweden

' National Center for High Resolution Electron Microscopy, Lund University, Box 124, 22100 Lund, Sweden
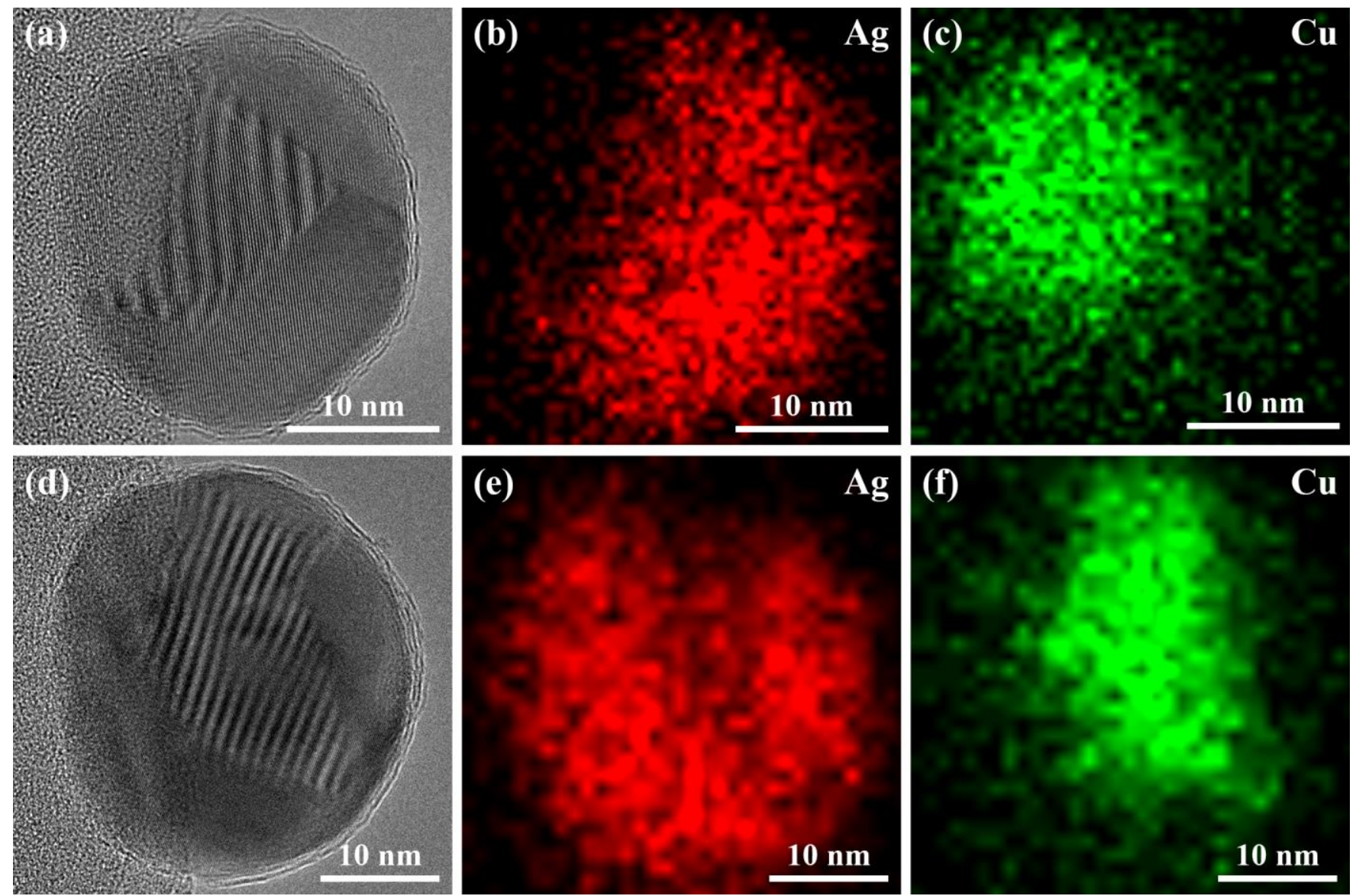

Figure S1. (a+d) HRTEM images of as-deposited bimetallic Ag-Cu nanoparticles heated up to $350^{\circ} \mathrm{C}$. Multiple heterointerfaces are present in each nanoparticle, and oxides/C-based contamination cover(s) the surfaces. The diameters of both nanoparticles are in good agreement with the chosen diameter of $30 \mathrm{~nm}$ for the deposition of bimetallic nanoparticles generated in a spark ablation system on the MEMS-based heating chip. STEM-EDS elemental maps of (b+e) Ag $\left(\mathrm{L} \alpha_{1}\right)$ and $(\mathrm{c}+\mathrm{f}) \mathrm{Cu}\left(\mathrm{K} \alpha_{1}\right)$ corresponding to the nanoparticles presented in $(\mathrm{a}+\mathrm{d}) .8 \mathrm{Ag}-\mathrm{Cu}$ nanoparticles (including those shown here) were analyzed to determine an average composition of $56.24 \pm 9.51$ atom $\% \mathrm{Ag}$ (L series) and $43.76 \pm 9.51$ atom $\% \mathrm{Cu}$ (K series). 


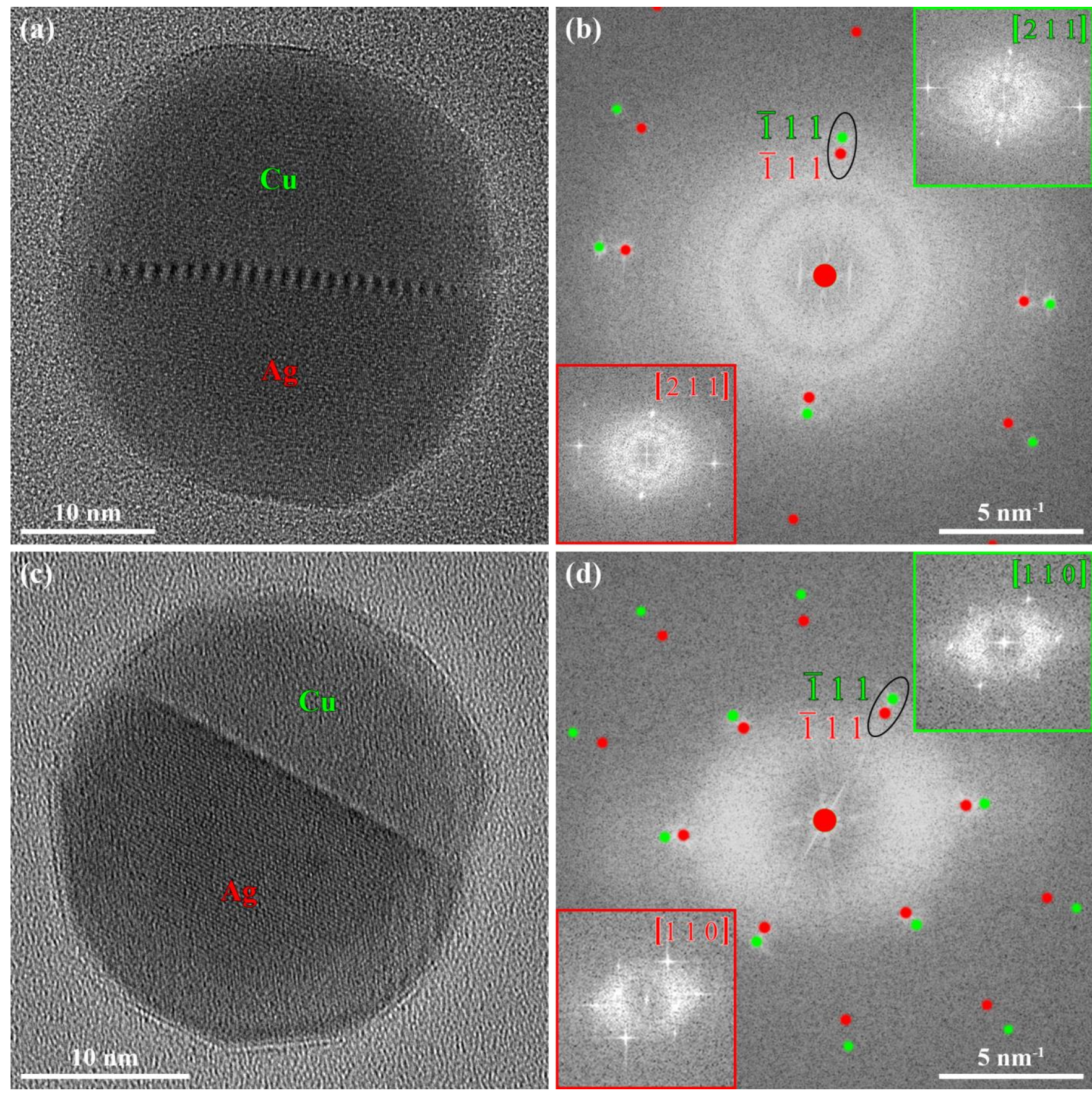

Figure S2. $(\mathrm{a}+\mathrm{c})$ HRTEM images of $\mathrm{Ag}-\mathrm{Cu}$ nanoparticle heterostructures observed after $\mathrm{H}_{2}$ treatment at $500-650{ }^{\circ} \mathrm{C}$. Both heterointerfaces are tilted close to parallel to the electron beam. (b+d) All phases are oriented close to one of their zone axes as highlighted in the insets, and the corresponding power spectra with overlaid simulated electron diffraction patterns of the cubic $\mathrm{Ag}$ (red) and $\mathrm{Cu}$ (green) phases reveal the involvement of $\{111\}$ facets in the heterointerface formation. 

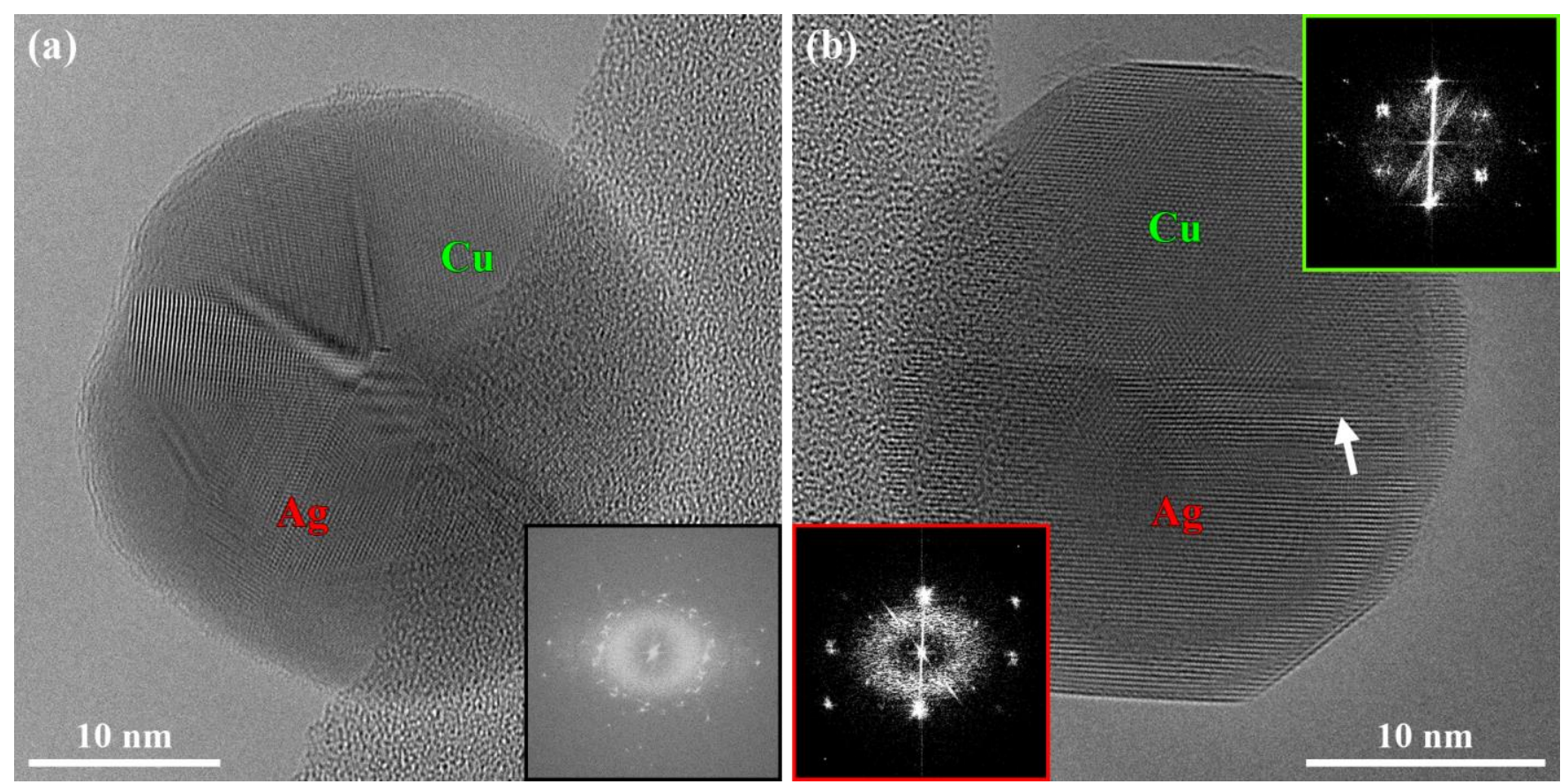

Figure S3. HRTEM images of Ag-Cu nanoparticles without a sharp $\mathrm{Ag}\{111\} / \mathrm{Cu}\{111\}$ interface after $\mathrm{H}_{2}$ treatment at $500-650{ }^{\circ} \mathrm{C}$. (a) Both phases reveal a high number of defects, which is supported by the corresponding power spectrum as inset. (b) The presence of crystal defects usually leads to rough heterointerfaces highlighted by a white arrow. The power spectra of the Ag (red, bottom left) and $\mathrm{Cu}$ (green, top right) phases shown as insets of (b) are altered in brightness and contrast to reveal the addressed presence of defects. 

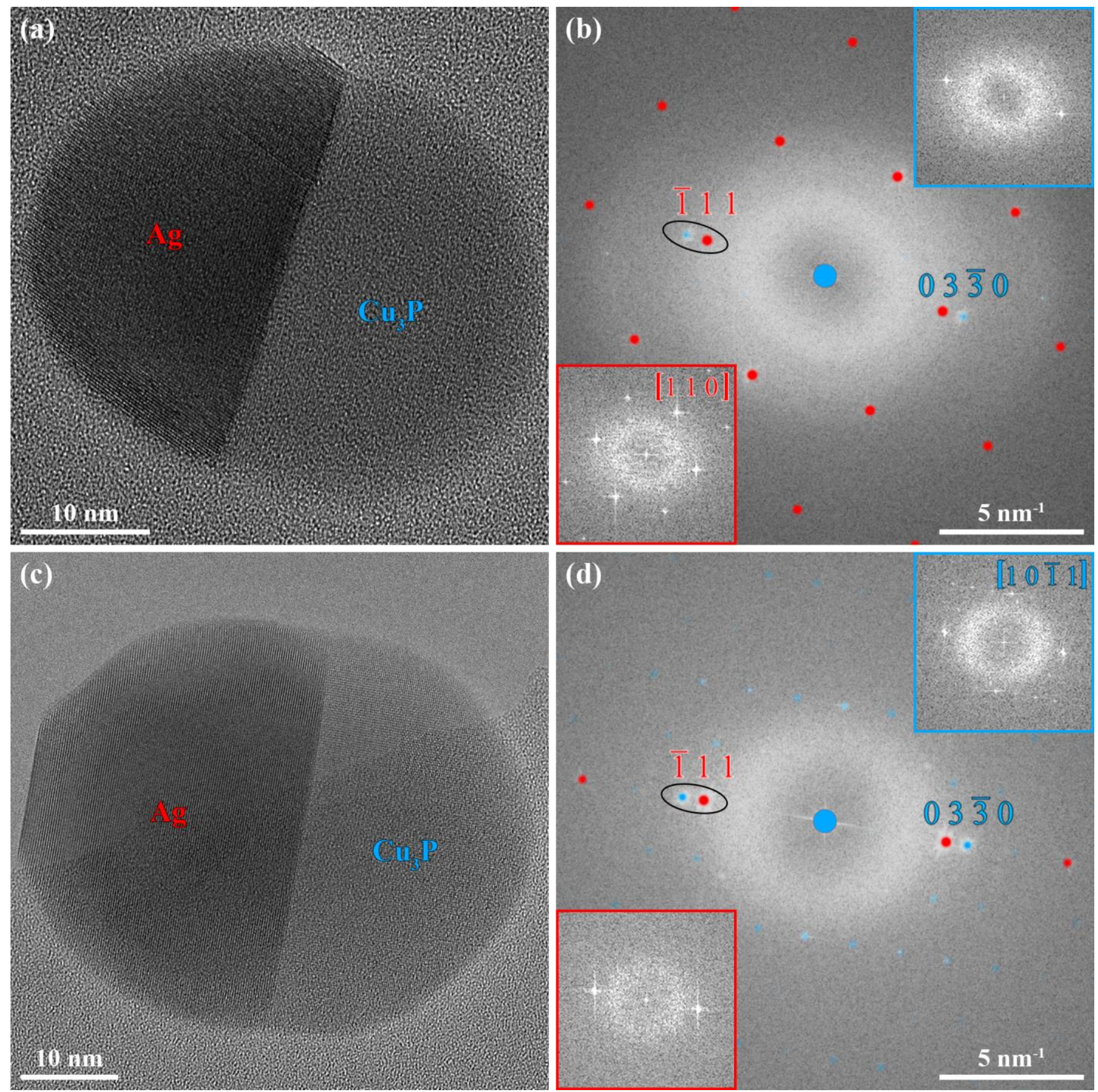

Figure $\mathrm{S}_{4}$. (a) HRTEM image of a $\mathrm{Ag}-\mathrm{Cu}_{3} \mathrm{P}$ nanoparticle heterostructure with a single interface. (b) The power spectrum corresponding to (a) with overlaid simulated electron diffraction patterns confirms the presence of a $\operatorname{Ag}(\overline{1} 11) / \mathrm{Cu} u_{3} \mathrm{P}(\mathrm{o} \overline{3} 30)$ interface. The insets in (b) reveal the $\mathrm{Ag}$ phase (red, bottom left) tilted close to its [110] zone axis and the $\mathrm{Cu}_{3} \mathrm{P}$ phase (blue, top right) tilted off its zone axis. (c) HRTEM image of a $\mathrm{Ag}-\mathrm{Cu}_{3} \mathrm{P}$ nanoparticle heterostructure with a significantly larger diameter of $\sim 45 \mathrm{~nm}$. (d) The heterointerface is again formed by $\mathrm{Ag}(\overline{\mathrm{n}} 11)$ and $\mathrm{Cu}_{3} \mathrm{P}(\mathrm{o} \overline{3} 30)$ planes as highlighted by the power spectrum associated with (c) with overlaid simulated electron diffraction patterns. The insets in $(\mathrm{d})$ show that the $\mathrm{Cu}_{3} \mathrm{P}$ phase (blue, top right) is tilted close to its [10ī] zone axis and the Ag phase (red, bottom left) is tilted off its zone axis. 

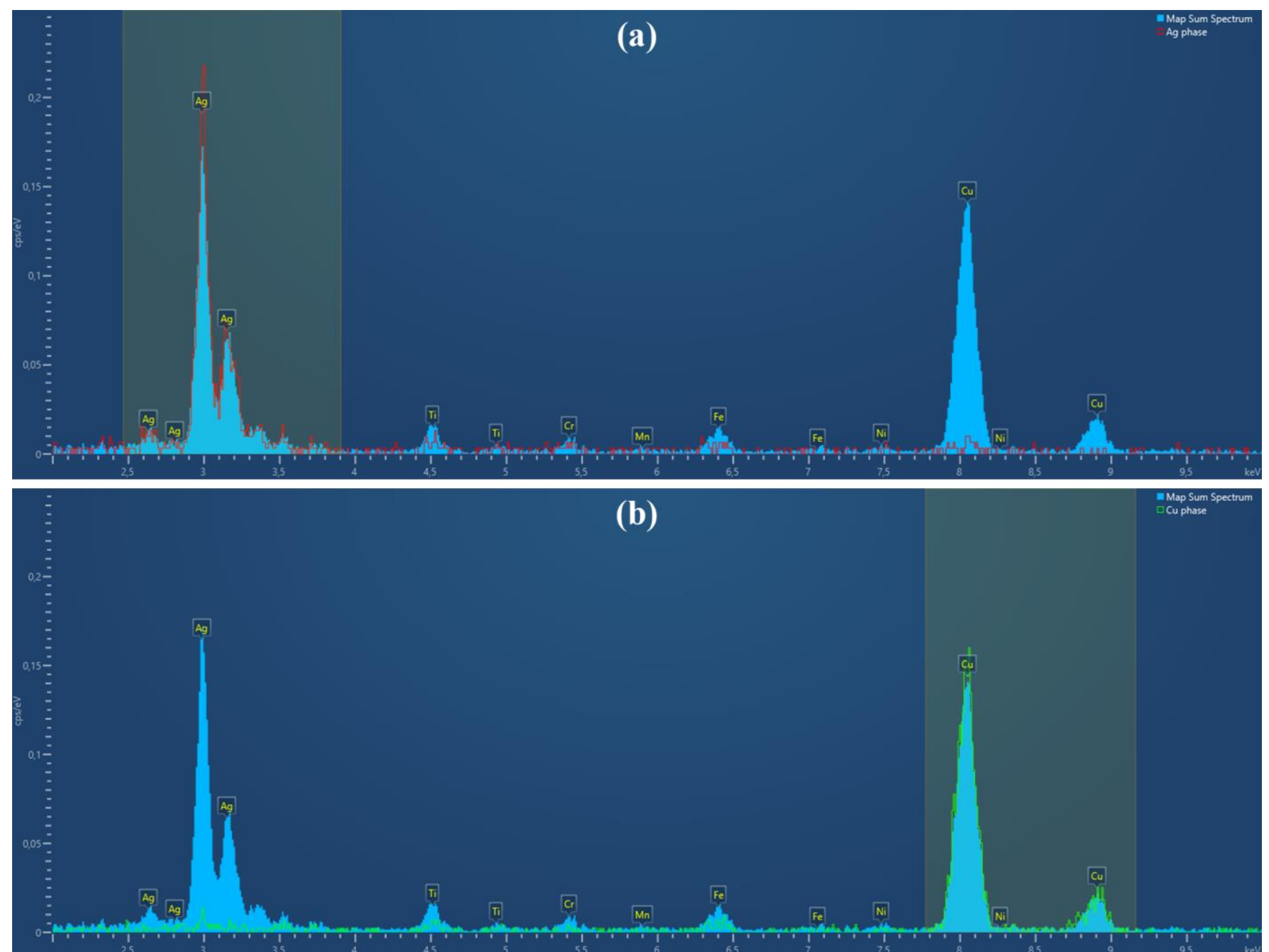

Figure S5. EDS sum spectra of the STEM-EDS measurement of the Ag-Cu nanoparticle presented in Figure 1 of the main manuscript. The EDS sum spectra of selected areas within the (a) Ag and (b) Cu phases are overlaid with the overall sum spectrum. The yellow areas represent the energy ranges used for normalization. Both elements show a very low solubility in each other $(\sim 3$ atom \%), which is in good agreement with the Ag-Cu binary phase diagram¹. The additional EDS peaks ( Ti, Cr, Mn, Fe, and Ni) obtained due to electron scattering can be allocated to the side port injector and the TEM holder material. 

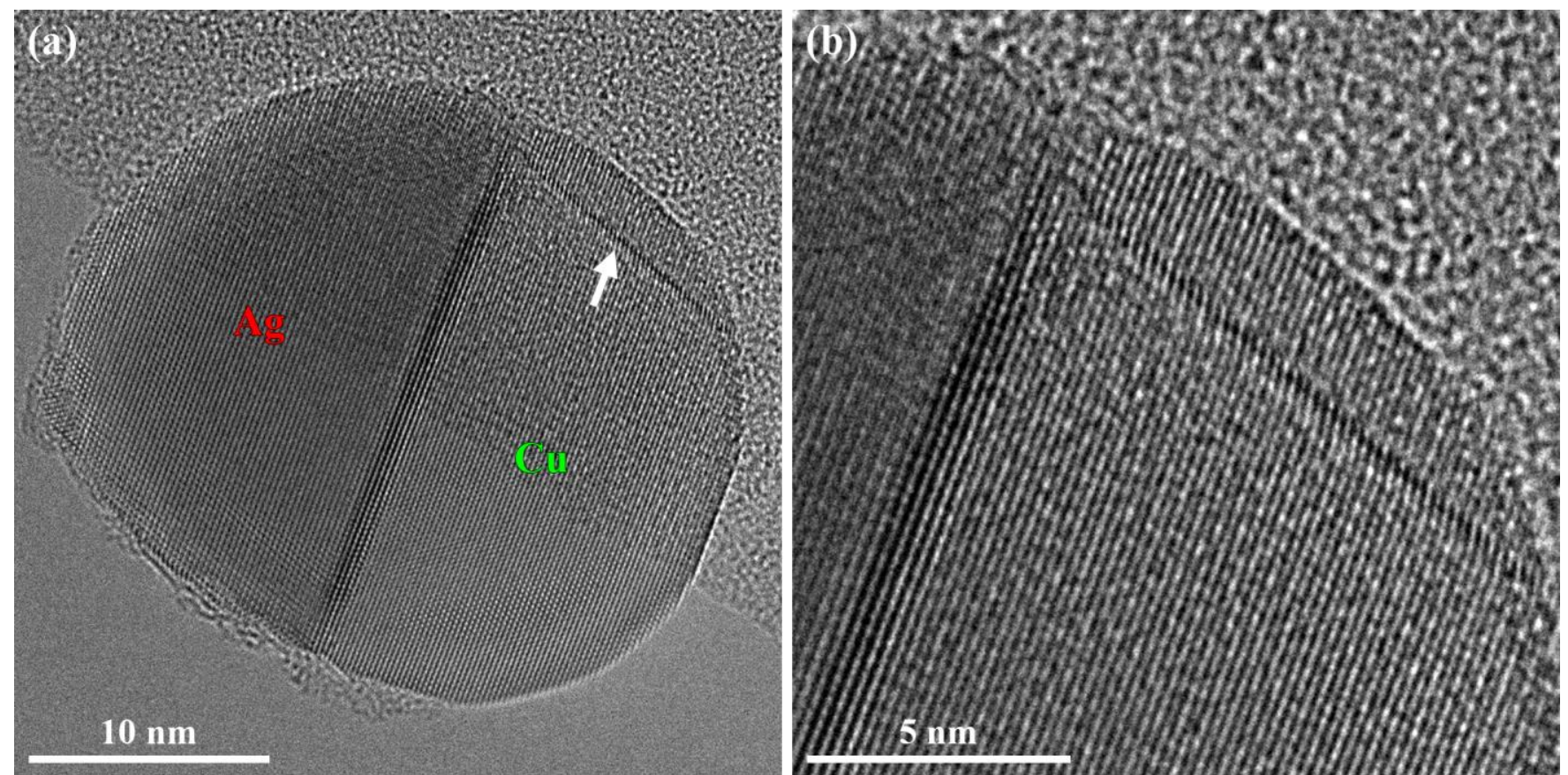

Figure S6. (a) HRTEM image of the same $\mathrm{Ag}-\mathrm{Cu}$ nanoparticle as shown in Figure 1 of the main manuscript acquired with underfocus. The white arrow highlights the presence of a defect in the region where heterointerface $\mathrm{I}_{5}$ formed after the complete transformation of $\mathrm{Cu}$ to $\mathrm{Cu}_{3} \mathrm{P}$ at a later stage of the experiment. (b) A zoomed-in region of the HRTEM image in (a) for a better visualization of the addressed defect. 


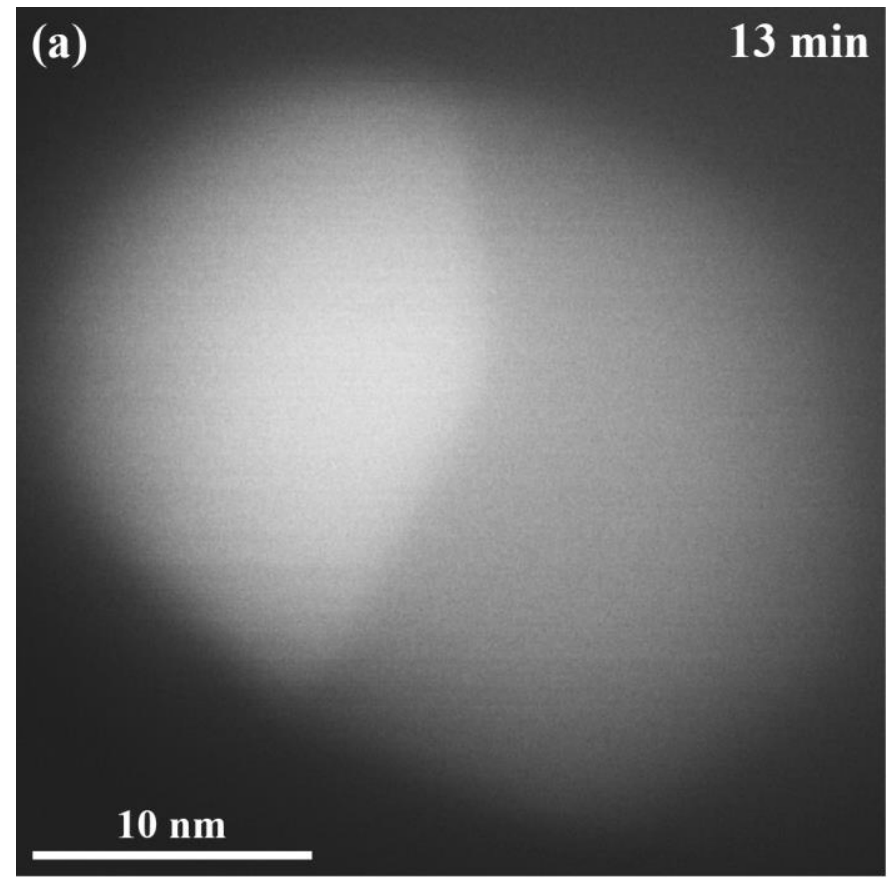

\section{(b)}
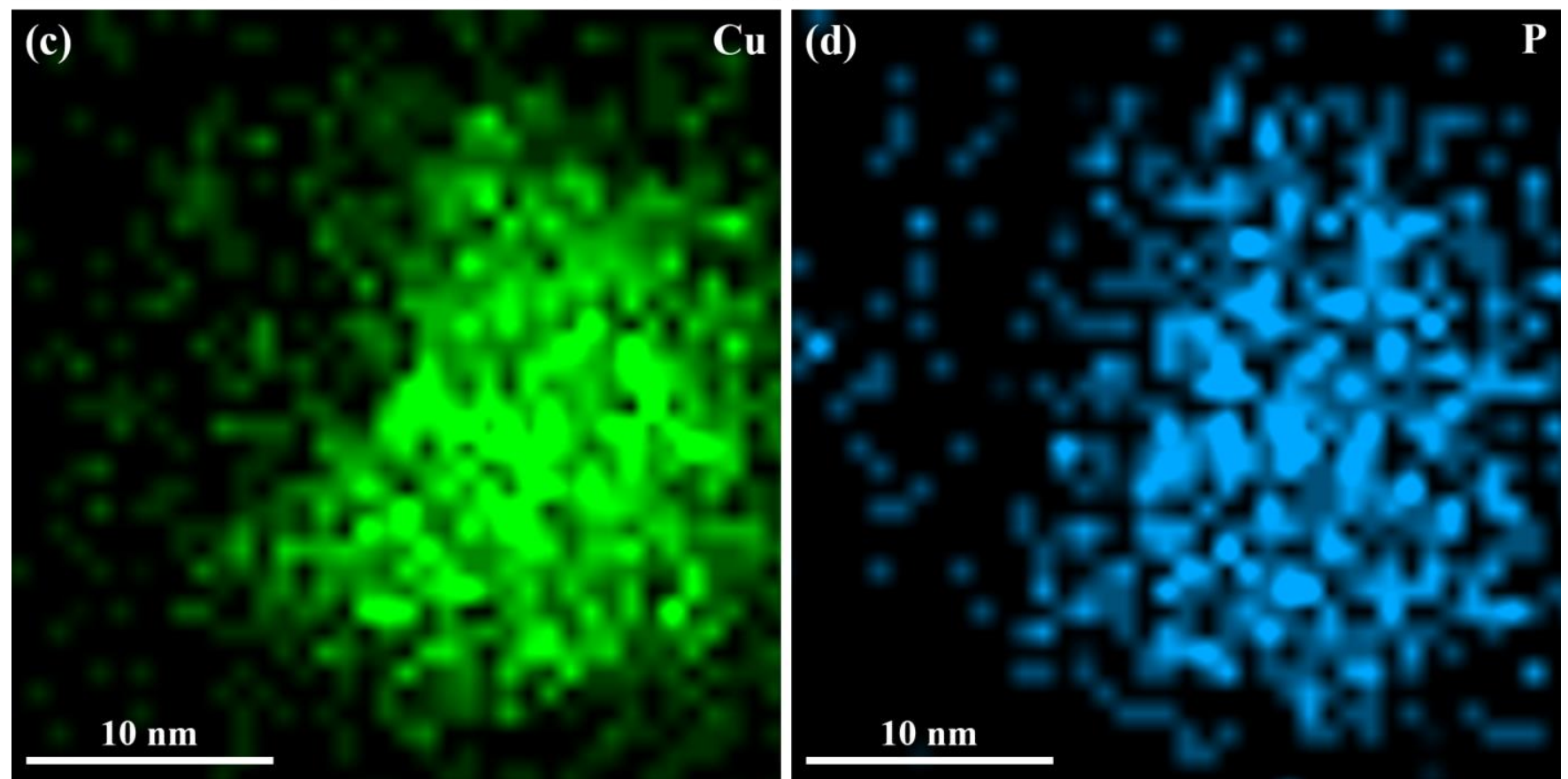

Figure S7. (a) HAADF-STEM image of the $\mathrm{Ag}-\mathrm{Cu}_{3} \mathrm{P}$ nanoparticle heterostructure presented in Figure 4a of the main manuscript

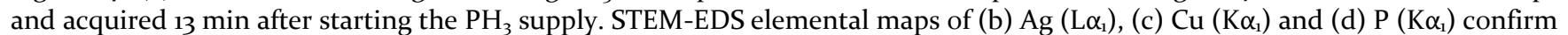
the exclusive chemical reaction of $\mathrm{PH}_{3}$ with $\mathrm{Cu}$. The $\mathrm{Ag}-\mathrm{Cu}_{3} \mathrm{P}$ nanoparticle heterostructure contains 38.82 atom \% Ag ( $\mathrm{L}$ series), 41.82 atom $\% \mathrm{Cu}$ (K series) and 19.36 atom \% $\mathrm{P}$ (K series). The $\mathrm{Cu}: \mathrm{P}$ atomic ratio is significantly lower than 3:1 (2.16:1), which is in agreement with previous studies suggesting a high concentration of $\mathrm{Cu}$ vacancies in hexagonal $\mathrm{Cu}_{3} \mathrm{P}^{2-3}$. The $\mathrm{Cu}_{3} \mathrm{P}$ phases in $8 \mathrm{Ag}^{-}$ $\mathrm{Cu}_{3} \mathrm{P}$ nanoparticle heterostructures (including the one presented here) synthesized under similar conditions have been analyzed to determine an average composition of $71.71 \pm 2.52$ atom \% Cu (K series) and 28.29 \pm 2.52 atom \% $\mathrm{P}$ (K series) giving an average $\mathrm{Cu}: \mathrm{P}$ atomic ratio of 2.53:1. 


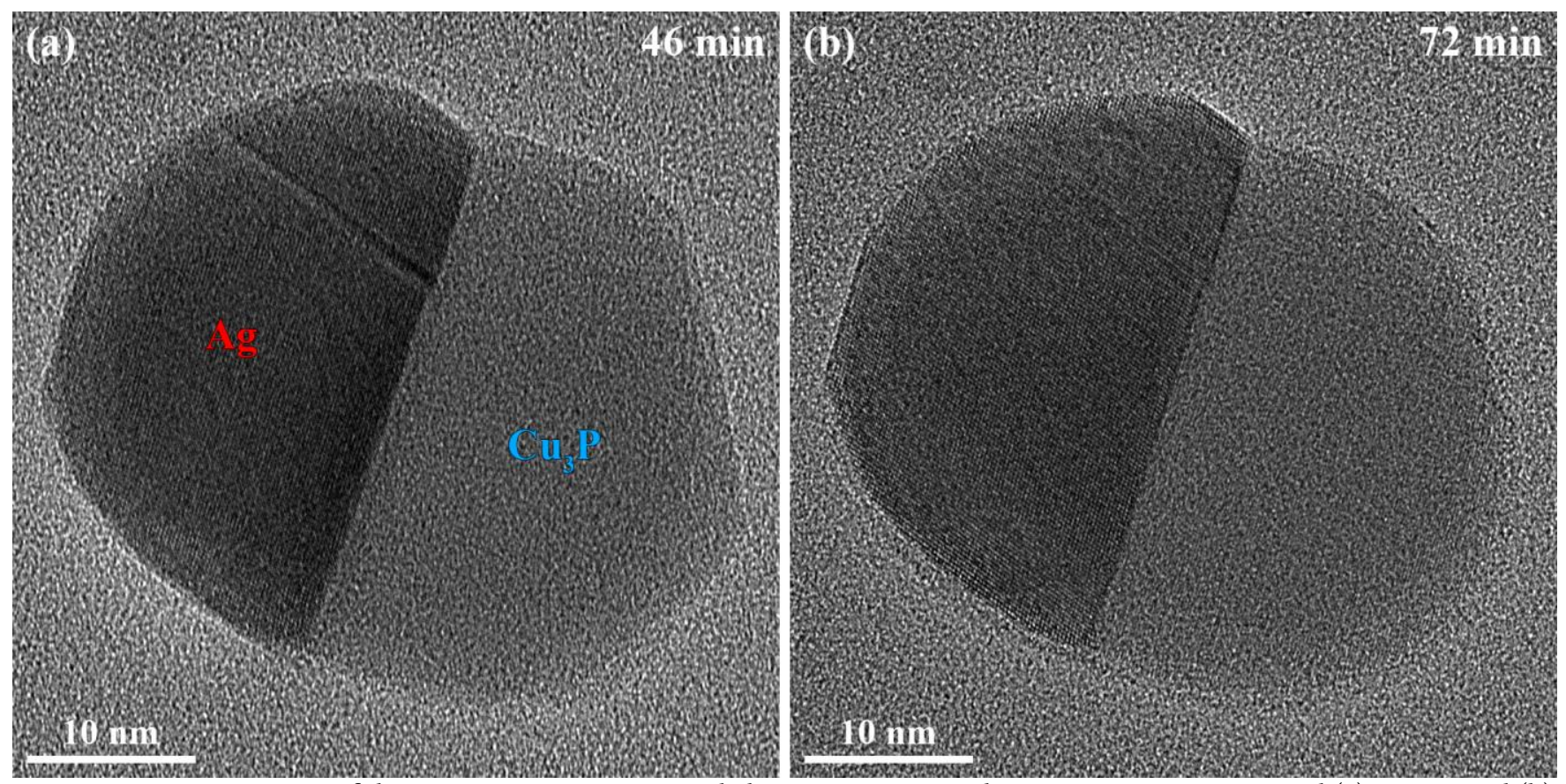

Figure S8. HRTEM images of the same $\mathrm{Ag}-\mathrm{Cu}_{3} \mathrm{P}$ nanoparticle heterostructure as shown in Figure $\mathrm{S} 4 \mathrm{a}$ acquired (a) 46 min and (b) 72 min after stopping the supply of $\mathrm{PH}_{3}$ at $350{ }^{\circ} \mathrm{C}$. (a) Faceting of the $\mathrm{Cu}_{3} \mathrm{P}$ phase (right) of the nanoparticle heterostructure is visible. (b) Corner truncation leads to a physical transformation of the $\mathrm{Cu}_{3} \mathrm{P}$ phase. 


\section{Defocus (nm)}

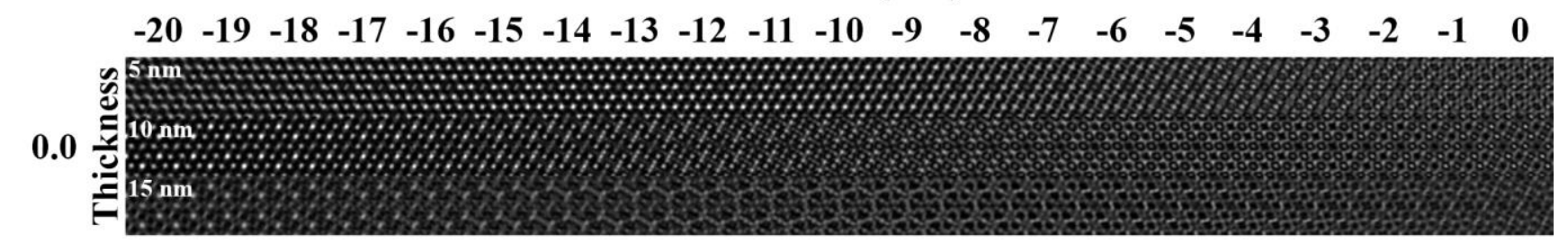

0.2

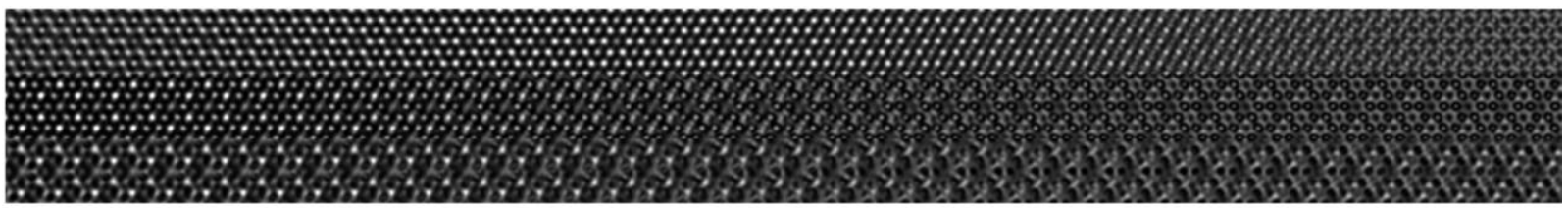

0.4
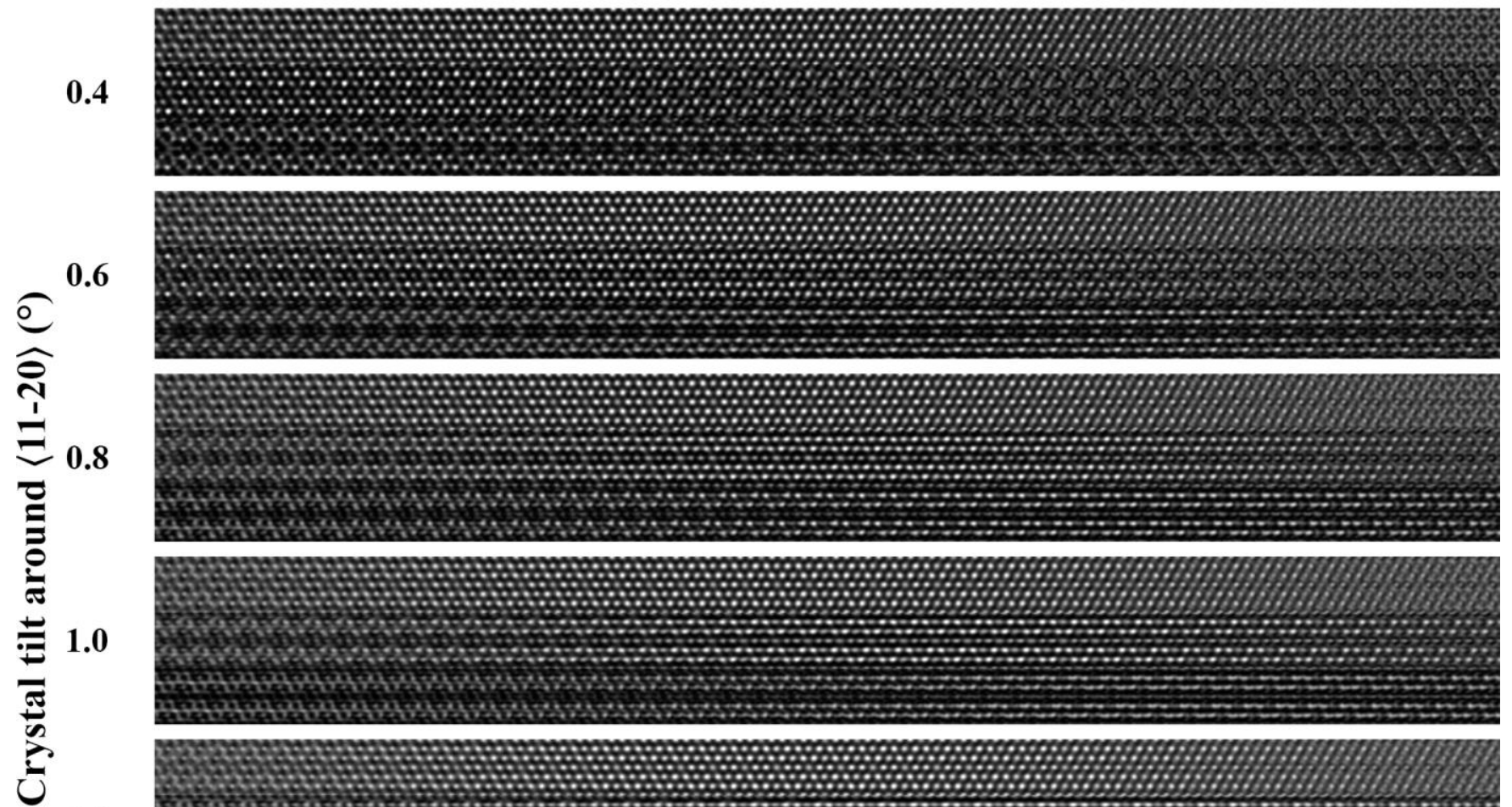

1.2
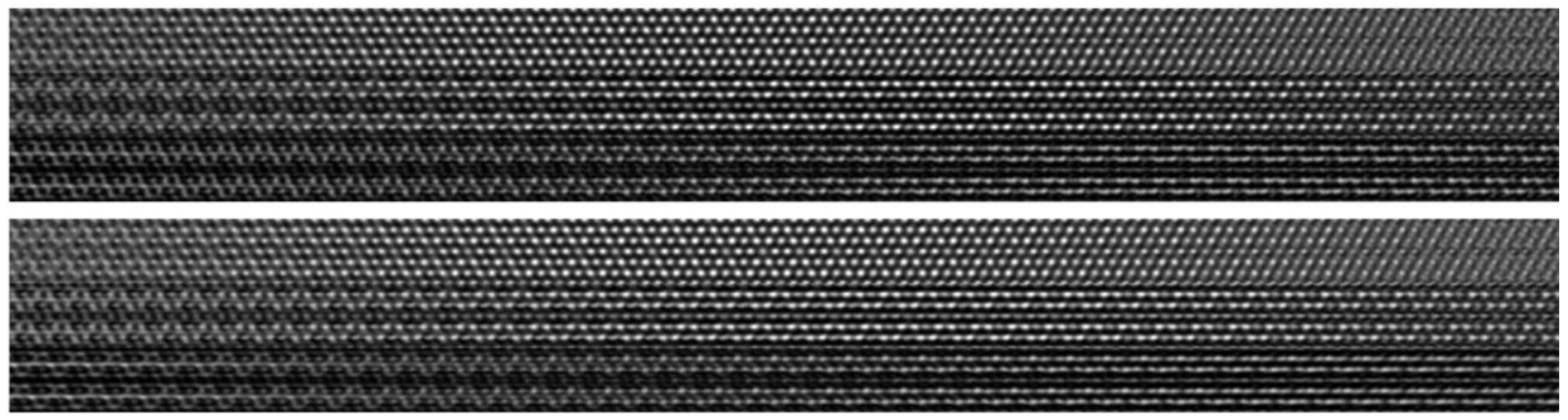

1.4

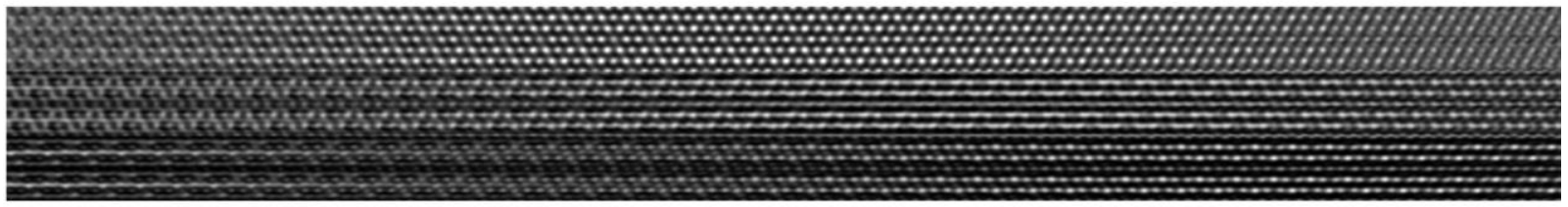

1.6

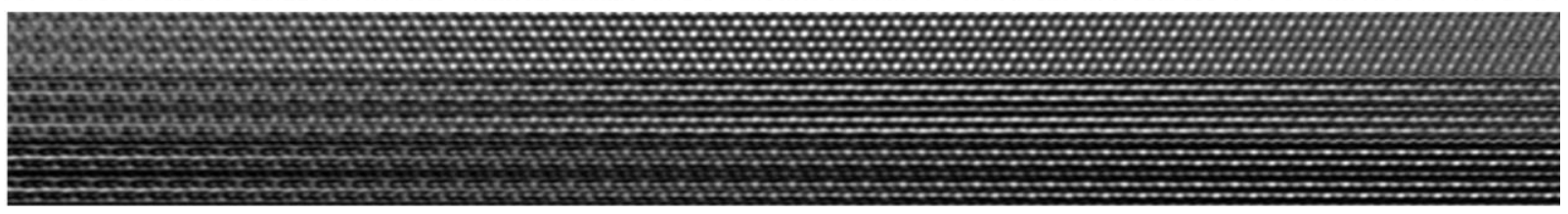

1.8

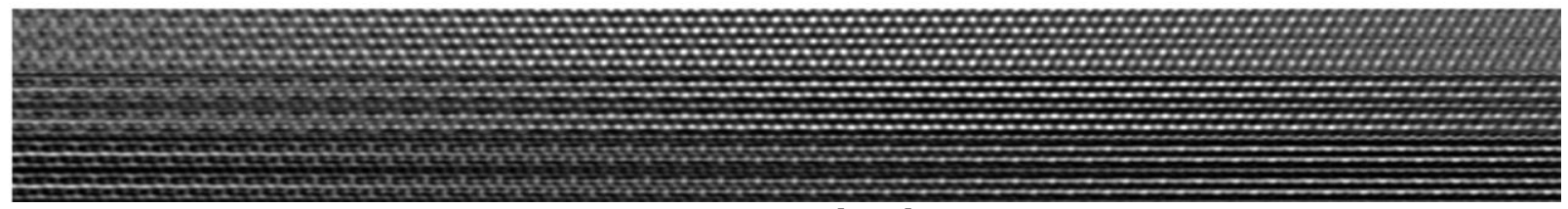

Figure S9. Simulation of HRTEM images of a $\mathrm{Cu}_{3} \mathrm{P}$ crystal oriented in its [ooor] zone axis with different thicknesses for specific defocus values and crystal tilts around the $\langle 11 \overline{2} \mathrm{O}\rangle$ direction. 


\section{Defocus (nm)}

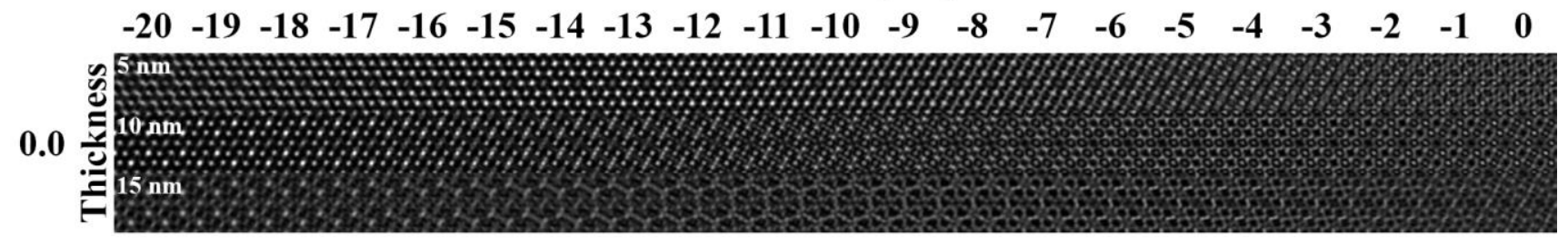

0.2

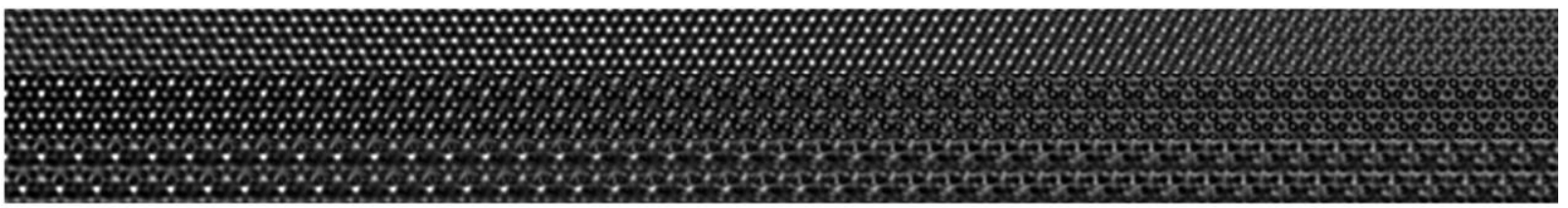

0.4
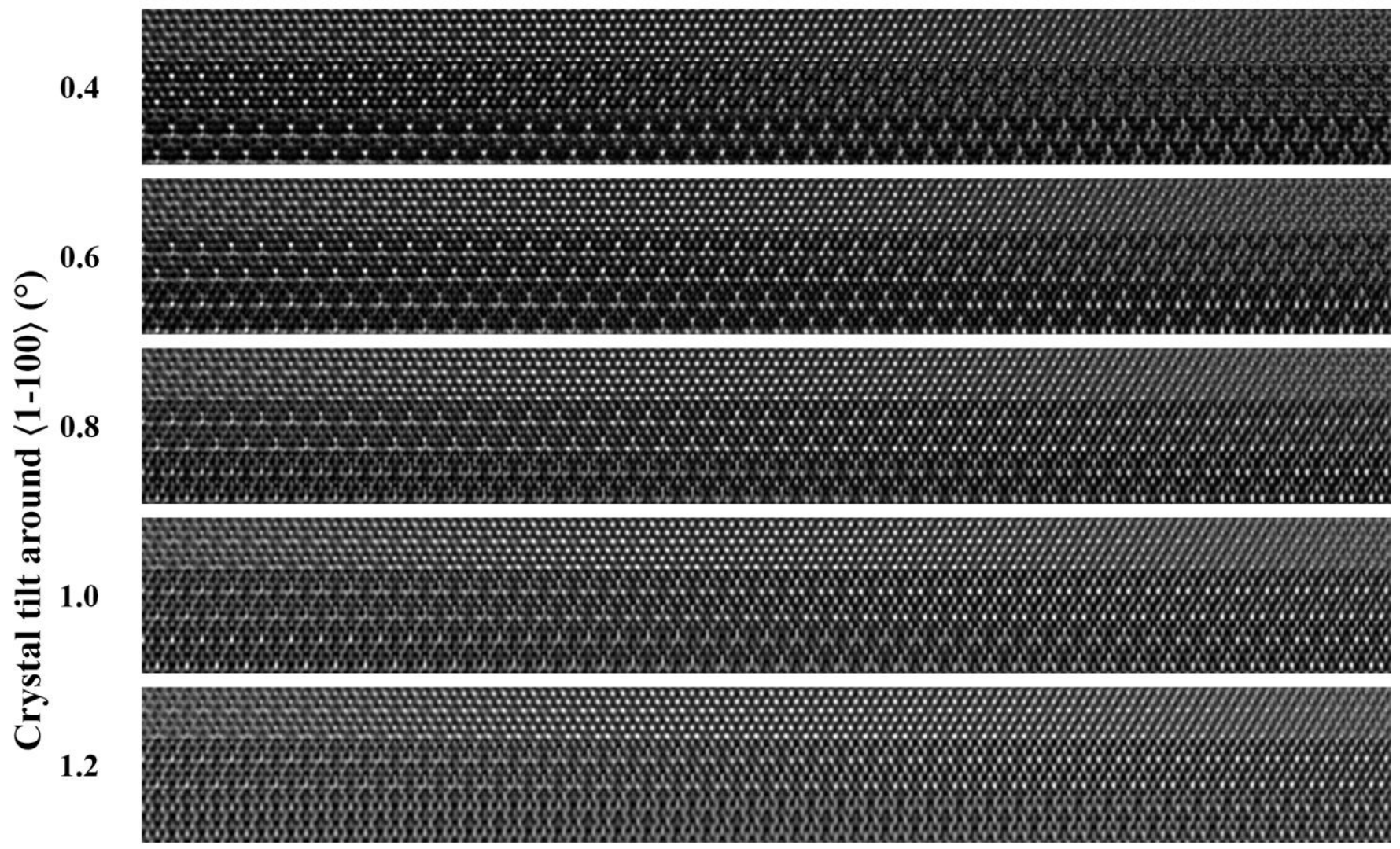

\section{4}

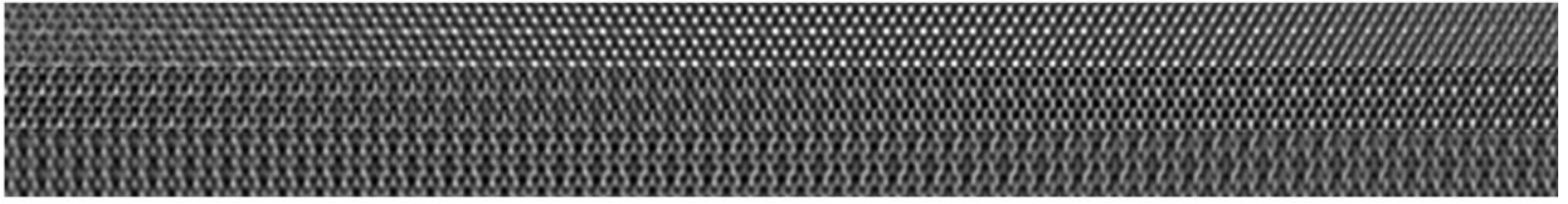

1.6

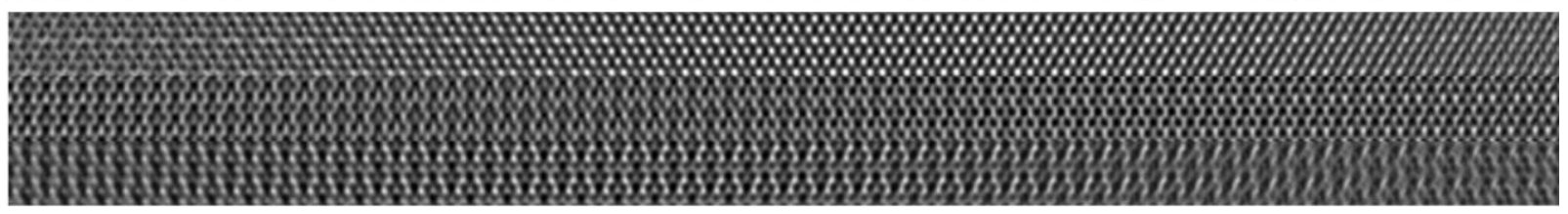

1.8

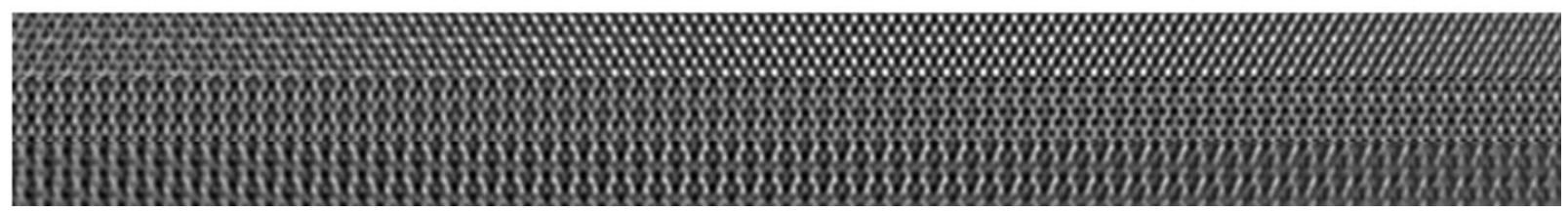

Figure Sio. Simulation of HRTEM images of a $\mathrm{Cu}_{3} \mathrm{P}$ crystal oriented in its [0ool] zone axis with different thicknesses for specific defocus values and crystal tilts around the $\langle\overline{1} \overline{0} 0\rangle\rangle$ direction. 

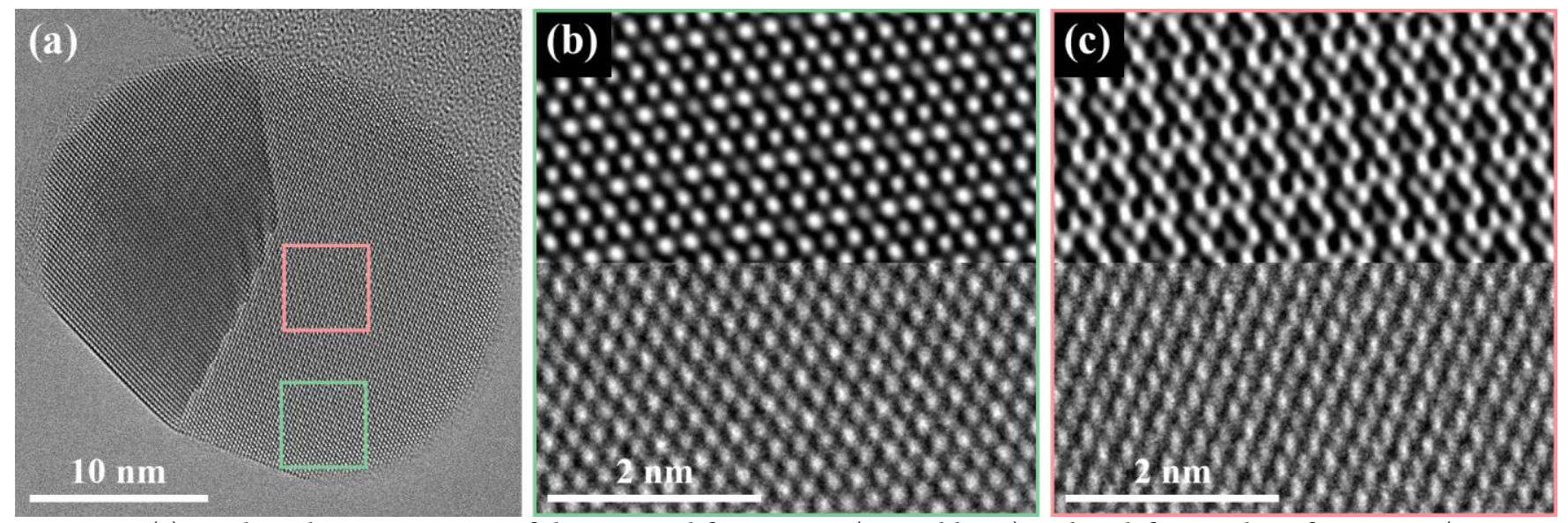

Figure S11. (a) A selected HRTEM image of the acquired focus series (see Table S6) with a defocus value of $-4.66 \mathrm{~nm}(-5.10 \mathrm{~nm}$ according to the refinement of the exit wavefunction reconstruction (see Table $\left.\mathrm{S}_{7}\right)$ ). The (b) thin and (c) thick regions of the $\mathrm{Cu}_{3} \mathrm{P}$ crystal are indicated by green and pink rectangles in (a). The upper halves of the HRTEM images in (b) and (c) are matching simulations. The matching simulations (defocus: $-12 \mathrm{~nm}, 1.6^{\circ}$ tilt around the $\mathrm{Cu}_{3} \mathrm{P}$ [110o] direction (see Figure 5)) suggest the presence of (b) $5 \mathrm{~nm}$ and (c) $10 \mathrm{~nm}$ thick regions in the $\mathrm{Cu}_{3} \mathrm{P}$ crystal. A possible explanation for the different defocus values of the acquired image and the matching simulations could be a slight variation of the height along the nanoparticle heterostructure. The same parameters chosen for the multislice simulations to reconstruct the exit wavefunction are used for the HRTEM simulations (see Table $\mathrm{S}_{5}$ ). Straight before acquiring the focus series, the aberrations have been measured and are used for the HRTEM simulations $\left(A_{1}: 3.557 \mathrm{~nm} /-177 \cdot 9^{\circ}, B_{2}: 22.13 \mathrm{~nm} / 97.1^{\circ}, A_{2}: 52.29 \mathrm{~nm} / 39.6^{\circ}, C_{S}: 16.47 \mu \mathrm{m}\right)$. 


\section{Defocus (nm)}

$$
\begin{array}{lllllllllllllllllllll}
-20 & -19 & -18 & -17 & -16 & -15 & -14 & -13 & -12 & -11 & -10 & -9 & -8 & -7 & -6 & -5 & -4 & -3 & -2 & -1 & 0
\end{array}
$$

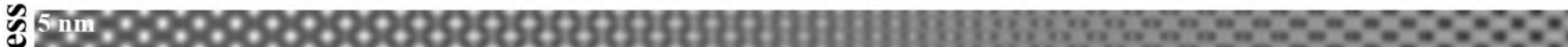

E $15 \mathrm{~nm}$

. $15 \mathrm{~nm}$

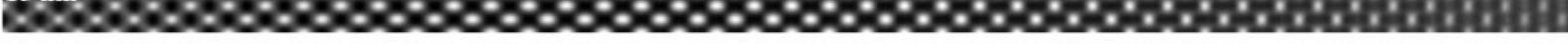

0.2
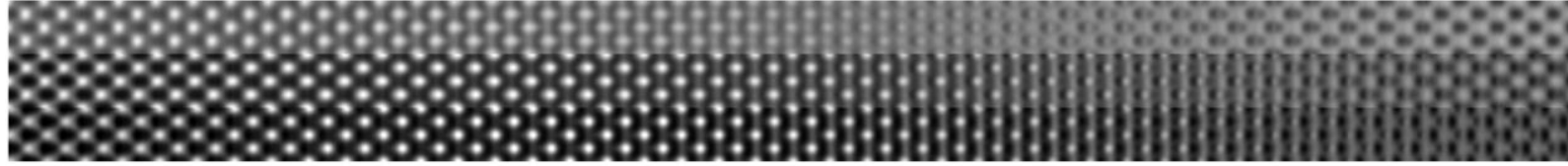

0.4

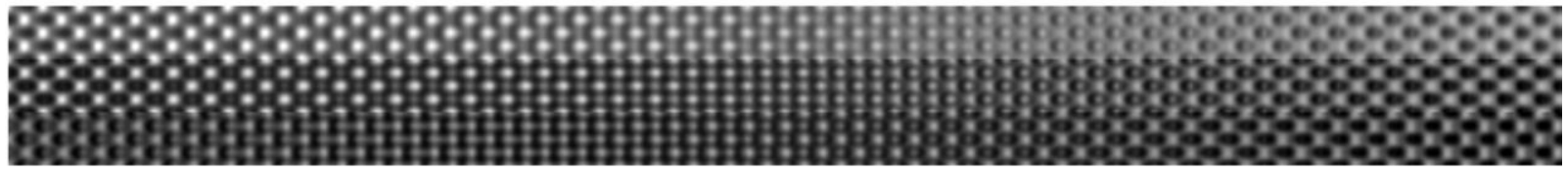

0.6
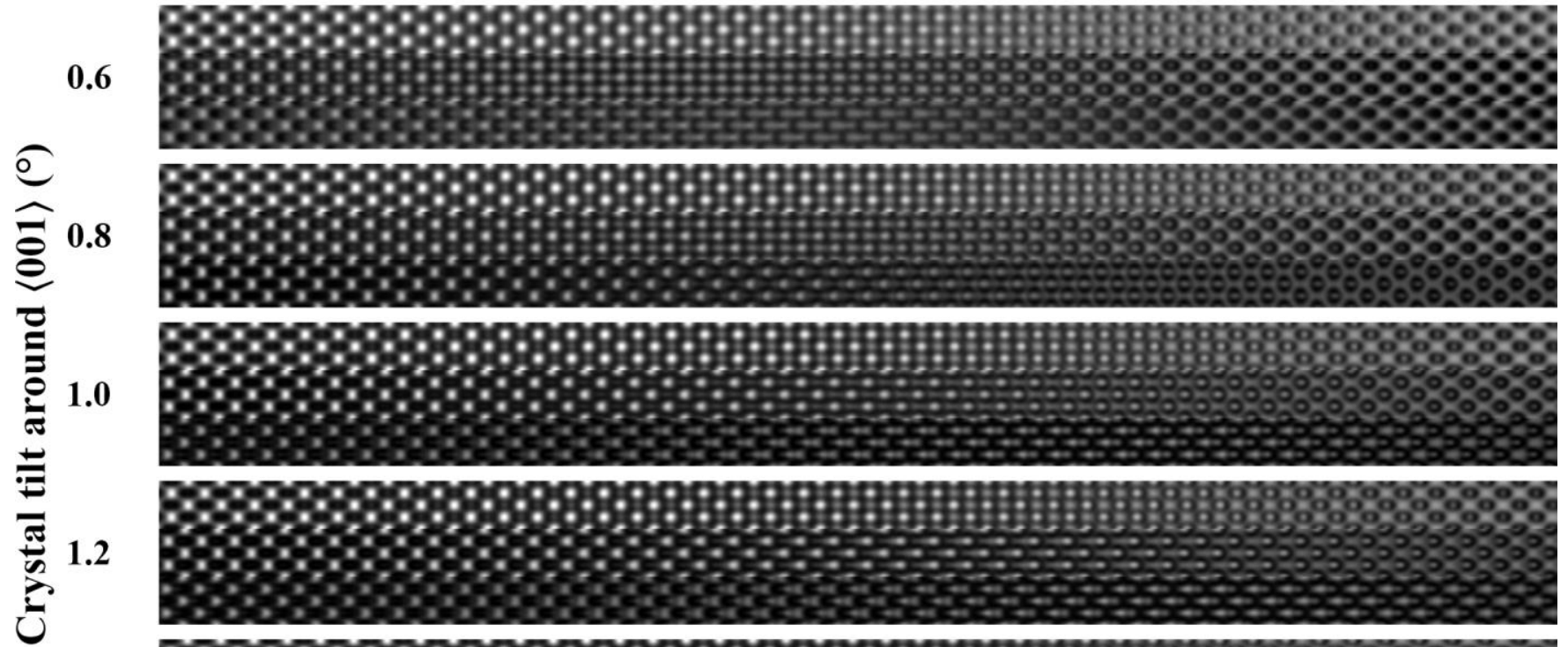

1.4

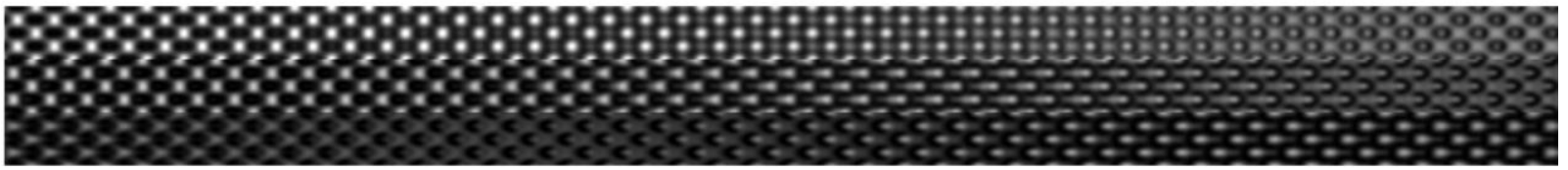

1.6
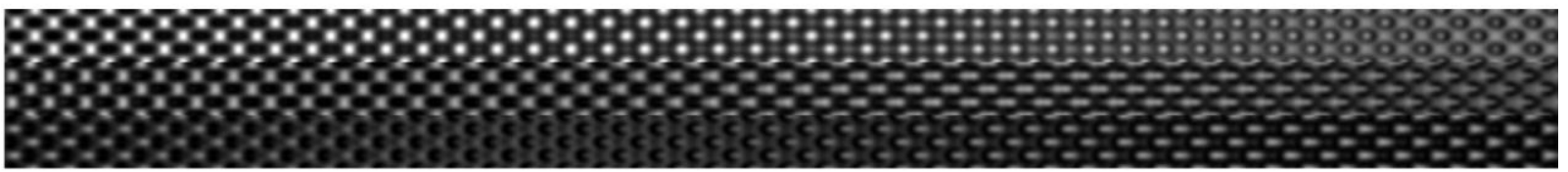

\section{8}

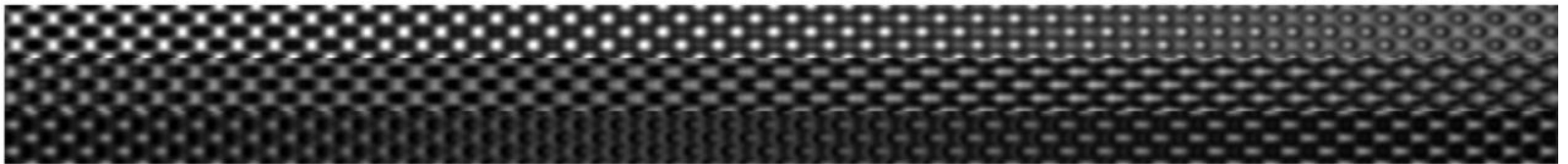

\section{0}

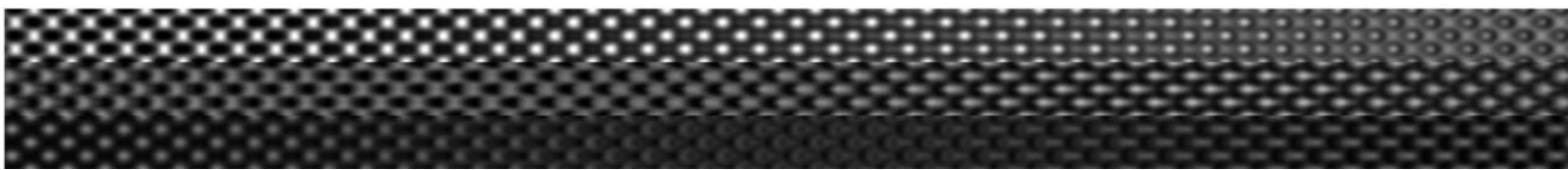

Figure S12. Simulation of HRTEM images of a Ag crystal oriented in its [110] zone axis with different thicknesses for specific defocus values and crystal tilts around the $\langle\mathrm{oo} 1\rangle$ direction. 

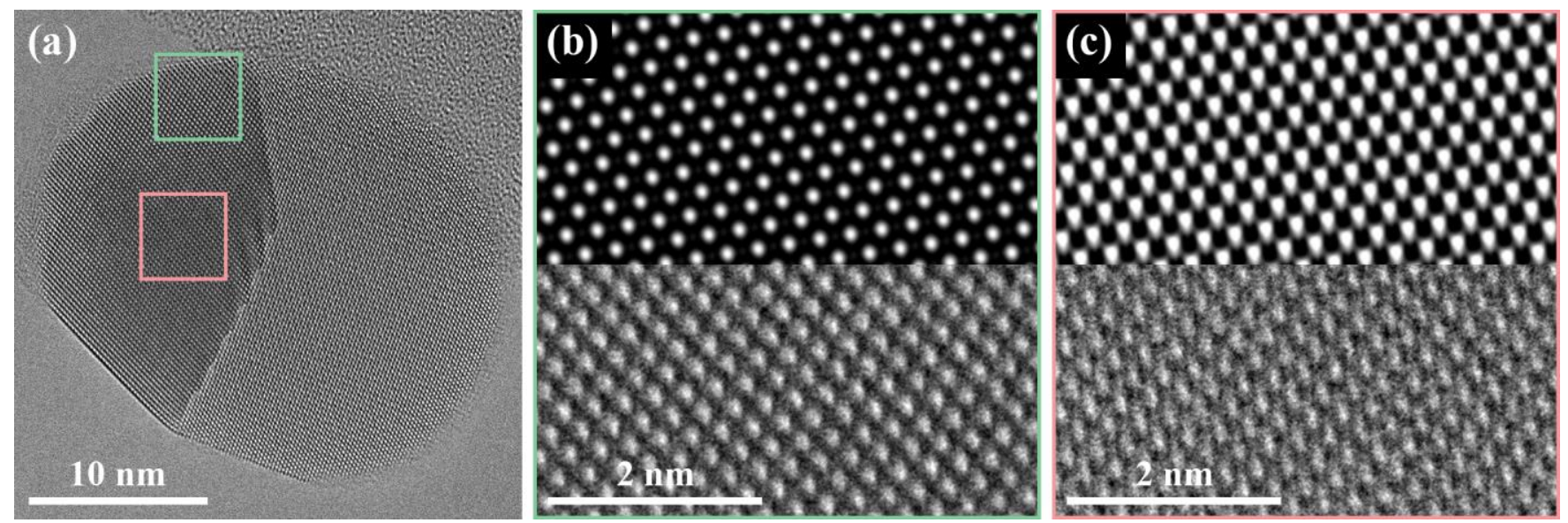

Figure S13. (a) HRTEM image of the acquired focus series (see Table S6) with a defocus value of $-4.66 \mathrm{~nm}(-5.10 \mathrm{~nm}$ according to the refinement of the exit wavefunction reconstruction (see Table $S_{7}$ )). The (b) thin and (c) thick regions of the Ag crystal are indicated by green and pink rectangles in (a). The upper halves of the HRTEM images in (b) and (c) are simulations for (b) $5 \mathrm{~nm}$ and (c) $10 \mathrm{~nm}$ with the same defocus values $(-12 \mathrm{~nm})$ and extents of tilt $\left(1.6^{\circ}\right)$ around the Ag [oo1] direction (see Figure 5) as determined in Figure $\mathrm{S} 11$ to match the $\mathrm{Cu}_{3} \mathrm{P}$ phase. Details about the multislice simulations are presented in Figure Sil. 

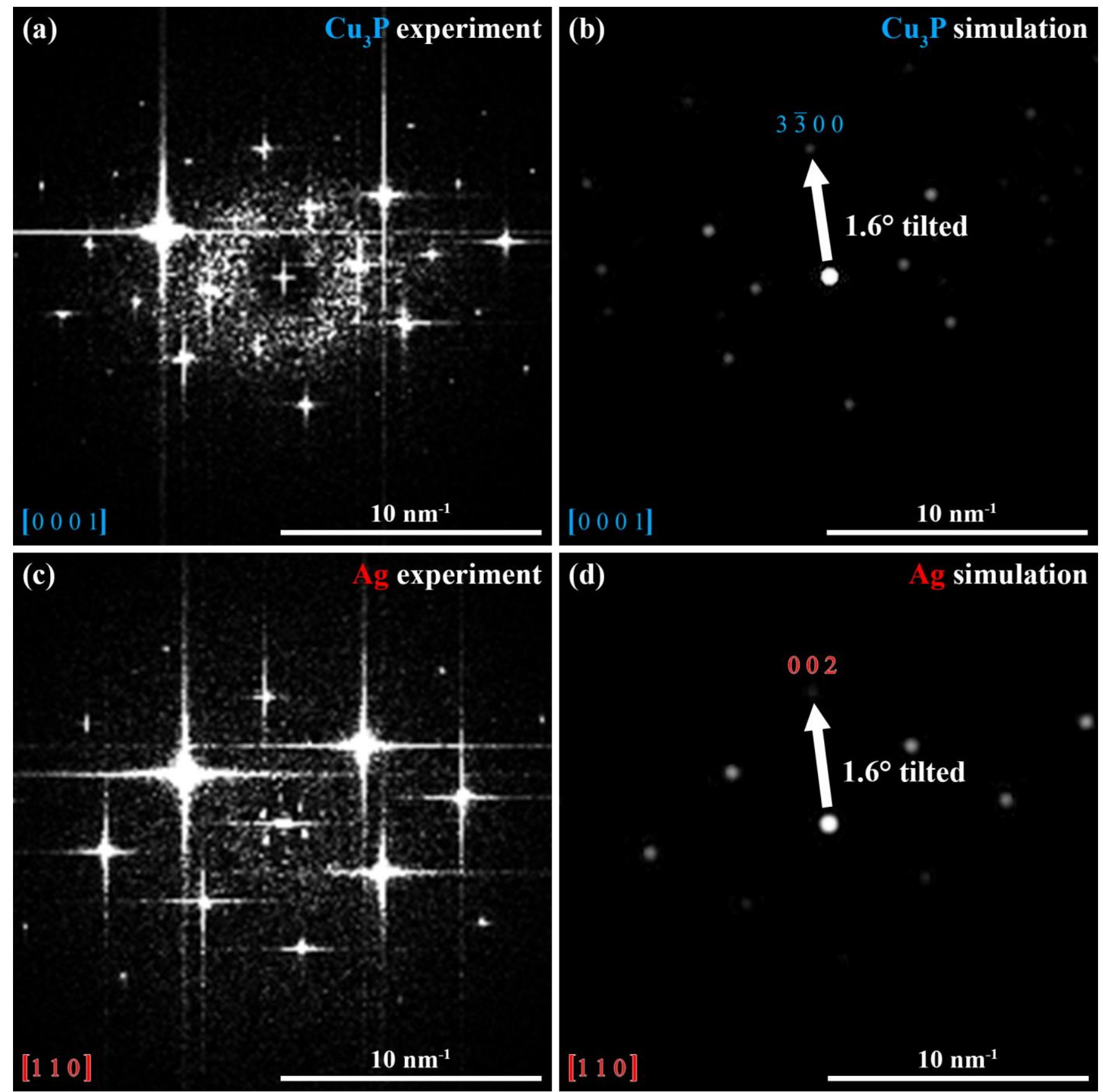

\section{(d)}

Ag simulation

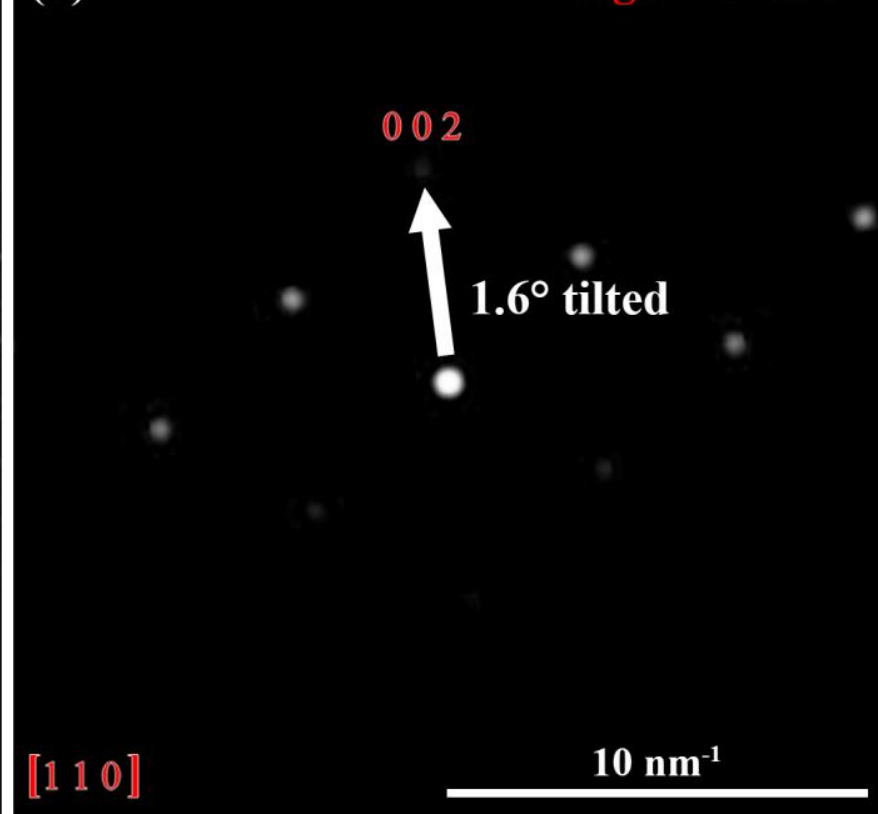

Figure S14. The squared moduli of the Fourier transform of the exit wavefunction for the (a) $\mathrm{Cu}_{3} \mathrm{P}$ and (c) $\mathrm{Ag}$ phases are compared with simulated SAED patterns (jems, multislice simulations) for the (b) $\mathrm{Cu}_{3} \mathrm{P}$ and (d) $\mathrm{Ag}$ phases with the determined tilt values of $1.6^{\circ}$ around the (b) $\mathrm{Cu}_{3} \mathrm{P}$ [110o] and (d) $\mathrm{Ag}$ [oo1] directions to confirm the results presented in Figures S9-13. The comparisons lead to the conclusion that both phases are slightly tilted off their zone axes in the same direction and to the same extent (not more than $\left.1.6^{\circ}\right)$. If the investigated areas of the $\mathrm{Ag}$ and $\mathrm{Cu}_{3} \mathrm{P}$ crystals were slightly thicker than expected $(>10 \mathrm{~nm})$, the extent of tilting off their zone axes would even be less. Therefore, the planes forming heterointerface I5 are expected to be very close to parallel. Simulations have been performed for $\sim 15 \mathrm{~nm}$ thick crystals. For better qualitative comparisons of the experimental data with the simulations, the brightness and contrast of the simulated SAED patterns have been slightly modified. 
(a)

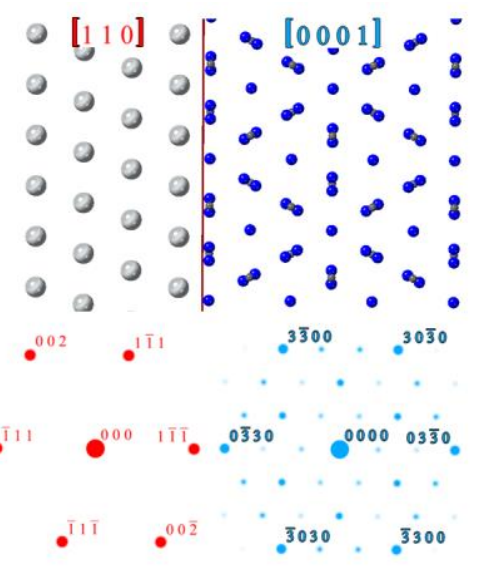

(b)

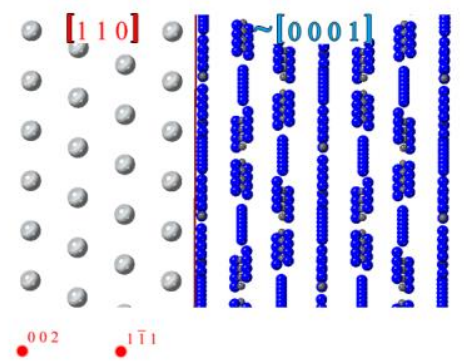

(c)

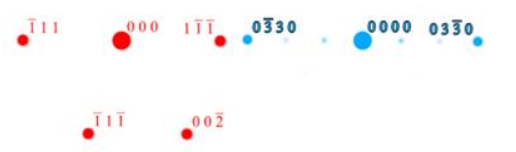

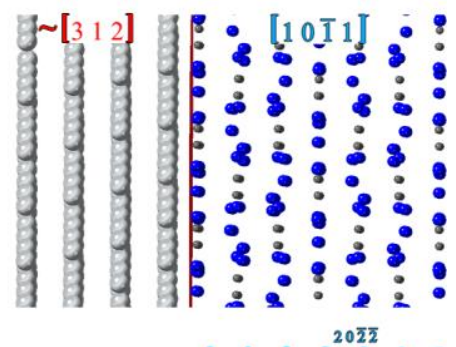

. . . ${ }^{20 \overline{2} \overline{2}}$. .

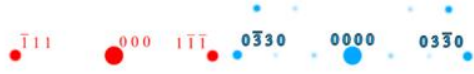

. ${ }^{\overline{2} 022} \ldots .$.

Figure $\mathrm{S}_{15}$. Atomic models of the $\mathrm{Ag}\left(\overline{1}_{11}\right) / \mathrm{Cu}_{3} \mathrm{P}(\mathrm{o} \overline{3} 30)$ interface and corresponding simulated electron diffraction patterns for nanoparticle heterostructures shown in (a) Figure 5a, (b) Figure S4a, and (c) Figure S4c. (a) The observed in-plane angular mismatch is not considered for this atomic model. The $\mathrm{Ag}$ phase is oriented in its [110] zone axis, while the $\mathrm{Cu}_{3} \mathrm{P}$ phase is oriented in its [oool] zone axis. Note that the phases are limited in their capability to rotate against each other due to the presence of heterointerface $\mathrm{I}_{5}$. In contrast to $(\mathrm{a})$, the $\mathrm{Ag}-\mathrm{Cu}_{3} \mathrm{P}$ nanoparticle heterostructures in $(\mathrm{b}+\mathrm{c})$ have a single $\mathrm{Ag}(\overline{\mathrm{n}} 11) / \mathrm{Cu} \mathrm{u}_{3} \mathrm{P}(\mathrm{o} \overline{3} 3 \mathrm{O}) \mathrm{interface}$. (b) The $\mathrm{Ag}$ phase is again oriented in its [110] zone axis, while the $\mathrm{Cu}_{3} \mathrm{P}$ phase is slightly rotated against the $\mathrm{Ag}$ phase $\left(\sim 3 \cdot 5^{\circ}\right.$ rotation of the $\mathrm{Cu}_{3} \mathrm{P}$ phase in (a) to match the power spectrum in Figure $4 \mathrm{~b}$ ). Therefore, we conclude that the phases' freedom to rotate against each other yields a slightly different arrangement than observed for heterointerface I4 in Figure $5 \mathrm{a}$. (c) A $48^{\circ}$-rotation of the model in (b) matches the experimental observations in Figures $\mathrm{S}_{4} \mathrm{c}$ and $\mathrm{S}_{4} \mathrm{~d}$. Consequently, there likely exists a preferred arrangement for $\mathrm{Ag}(\overline{1} 11)$ and $\mathrm{Cu}_{3} \mathrm{P}(\mathrm{o} \overline{3} 30)$ planes forming a heterointerface. 
Table S1. Acquisition parameters used for HRTEM images.

\begin{tabular}{|c|c|}
\hline HRTEM image & Electron dose rate $\left(\mathrm{e} / \AA^{2} \mathrm{~s}\right)$ \\
\hline Figure 1a & $\sim 3500$ \\
\hline Figure 5a & $\sim 3500$ \\
\hline Figure 6a & $\sim 4600$ \\
\hline Figure Sia & $\sim 2100$ \\
\hline Figure S1d & $\sim 1000$ \\
\hline Figure S2a & $\sim 10400$ \\
\hline Figure S2c & $\sim 5100$ \\
\hline Figure S3a & $\sim 9800$ \\
\hline Figure S3b & $\sim 7300$ \\
\hline Figure S4a & $\sim 4300$ \\
\hline Figure S4c & $\sim 2700$ \\
\hline Figure S6a & $\sim 3500$ \\
\hline Figure S8a & $\sim 4100$ \\
\hline Figure S8b & $\sim 4200$ \\
\hline
\end{tabular}

Table S2. Acquisition parameters used for HRTEM movies.

\begin{tabular}{|c|c|c|}
\hline HRTEM movie & Electron dose rate $\left(\mathrm{e} / \AA^{2} \mathrm{~s}\right)$ & Frame rate $(\mathrm{frames} / \mathrm{s})$ \\
\hline Movie S1 & $\sim 7800$ & $\mathbf{2 0}$ \\
\hline Movie S2 & $\sim 1600$ & $\mathbf{2 0}$ \\
\hline
\end{tabular}

Table S3. Acquisition parameters used for STEM-EDS elemental maps.

\begin{tabular}{|c|c|c|c|c|c|}
\hline $\begin{array}{c}\text { STEM-EDS ele- } \\
\text { mental map }\end{array}$ & Pixel size $(\mathrm{nm})$ & Binning & Time $(\mathrm{s})$ & Total counts & Scans \\
\hline Figures ic+d & 0.179 & 4 & 196 & 128566 & 11 \\
\hline Figures Sib+c & 0.139 & 4 & 185 & 131196 & 7 \\
\hline Figures S1e+f & 0.139 & 8 & 130 & 102533 & 3 \\
\hline Figures S7b-d & 0.208 & 4 & 227 & 139283 & 17 \\
\hline
\end{tabular}

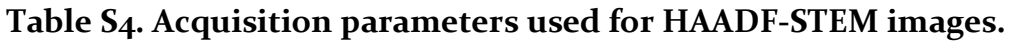

\begin{tabular}{|c|c|c|c|}
\hline HAADF-STEM image & Pixel size $(\mathrm{nm})$ & Dwell time $(\mu \mathrm{s})$ & Scans \\
\hline Figure S7a & 0.0521 & 10 & 1 \\
\hline
\end{tabular}

Table $S_{5}$. Parameters used for multislice simulations.

\begin{tabular}{|c|c|}
\hline Accelerating voltage & $300 \mathrm{kV}$ \\
\hline Coefficient of chromatic aberration, $C_{C}$ & $1.500 \mathrm{~mm}$ \\
\hline Coefficient of spherical aberration, $C_{S}$ & $0.016 \mathrm{~mm}$ \\
\hline Energy spread & $0.600 \mathrm{eV}$ \\
\hline Camera pixel size & $15 \mu \mathrm{m}$ \\
\hline Camera rows/columns & $4096 / 4096$ \\
\hline Magnification & 1500000 \\
\hline Illumination model & Envelope \\
\hline
\end{tabular}




\begin{tabular}{|c|c|}
\hline Beam half convergence & $1.0 \mathrm{mrad}$ \\
\hline Defocus spread & $2.0 \mathrm{~nm}$ \\
\hline Defocus minimum & $-10 \mathrm{~nm}$ \\
\hline Defocus step & $1.0 \mathrm{~nm}$ \\
\hline Defocus number & 21 \\
\hline Noise & o \% \\
\hline Multislice iterations: start after & o \\
\hline Multislice iterations: number & 1 \\
\hline Multislice iterations: increment & $5(\mathrm{Ag}) / 4\left(\mathrm{Cu}_{3} \mathrm{P}\right)$ \\
\hline Specimen thickness & $2.88 \mathrm{~nm}(\mathrm{Ag}) / 2.85 \mathrm{~nm}\left(\mathrm{Cu}_{3} \mathrm{P}\right)$ \\
\hline Atomic form factor & WKc. \\
\hline Potential generation & Direct \\
\hline Frozen lattice & Bicubic \\
\hline Temperature & $273.15 \mathrm{~K}$ \\
\hline Aperture diameter & $40.0 \mathrm{~nm}^{-1}$ \\
\hline
\end{tabular}

Table S6. Acquisition parameters used for the focus series.

\begin{tabular}{|c|c|c|c|c|}
\hline $\begin{array}{c}\text { Electron dose rate } \\
\left(\mathrm{e} / \AA^{2} \mathrm{~s}\right)\end{array}$ & Exposure time $(\mathrm{s})$ & $\begin{array}{c}\text { Defocus minimum } \\
(\mathrm{nm})\end{array}$ & Defocus step (nm) & Defocus number \\
\hline$\sim 3600$ & 1.0 & -9.32 & 4.66 & 11 \\
\hline
\end{tabular}

Table S7. Parameters used for exit wavefunction reconstructions.

\begin{tabular}{|c|c|}
\hline Accelerating voltage & $300 \mathrm{kV}$ \\
\hline Start defocus & -10 nm (simulations)/-9.32 nm (experiment) \\
\hline Defocus step & $\mathbf{1 ~ n m ~ ( s i m u l a t i o n s ) / 4 . 6 6 ~ n m ~ ( e x p e r i m e n t ) ~}$ \\
\hline Total images & 21 (simulations)/11 (experiment) \\
\hline Refinement-reconstruction cycles & 10 \\
\hline Maximum iteration cycles & 0.5 \\
\hline Noise control & 0.016 mm (simulations)/o.o1647 mm (experiment) \\
\hline Coefficient of spherical aberration, $C_{S}$ & $2.0 \mathrm{~nm}$ \\
\hline Defocus spread & $1.0 \mathrm{mrad}$ \\
\hline Beam convergence & \\
\hline
\end{tabular}

Table S8. Parameters used for simulations of electron diffraction patterns.

\begin{tabular}{|c|c|}
\hline Instrument: voltage & $300 \mathrm{kV}$ \\
\hline Instrument: convergence & $0.02 \AA^{-1}$ \\
\hline Detector: spot size & 100 \\
\hline Detector: saturation & 2 \\
\hline Detector: gamma & $100 \AA$ \\
\hline Sample: thickness & $100.0 \%$ \\
\hline Sample: vol. fraction & 2 \\
\hline
\end{tabular}




\section{References}

1. Subramanian, P. R.; Perepezko, J. H., The Ag-Cu (Silver-Copper) System. J. Phase Equilib. 1993, 14 (1), $62-75$.

2. De Trizio, L.; Gaspari, R.; Bertoni, G.; Kriegel, I.; Moretti, L.; Scotognella, F.; Maserati, L.; Zhang, Y.; Messina, G. C.; Prato, M.; Marras, S.; Cavalli, A.; Manna, L., $\mathrm{Cu}_{3-\mathrm{x}} \mathrm{P}$ Nanocrystals as a Material Platform for Near-Infrared Plasmonics and Cation Exchange Reactions. Chem. Mater. 2015, 27 (3), 1120-1128.

3. Wolff, A.; Doert, T.; Hunger, J.; Kaiser, M.; Pallmann, J.; Reinhold, R.; Yogendra, S.; Giebeler, L.; Sichelschmidt, J.; Schnelle, W.; Whiteside, R.; Gunaratne, H. Q. N.; Nockemann, P.; Weigand, J. J.; Brunner, E.; Ruck, M., Low-Temperature Tailoring of Copper-Deficient $\mathrm{Cu}_{3-\mathrm{x}} \mathrm{P}$-Electric Properties, Phase Transitions, and Performance in Lithium-Ion Batteries. Chem. Mater. 2018, 30 (20), 7111-7123. 